\title{
Acute Renal Failure in Horses with Rhabdomyolysis: An Insight into the Role of Oxidative Stress Injury
}

\section{Maged El-Ashker*}

Department of Internal Medicine and Infectious Diseases, Faculty of Veterinary Medicine, Mansoura University 35516, Egypt

Acute renal failure in horses is a potentially life threatening condition and frequently develops in clinical settings associated with increased urinary excretion of myoglobin. During physical exercise, oxygen flux to active skeletal muscles increases, which leads to enhanced production of reactive oxygen species and free radicals with a deleterious effect on cellular structures involved in physical activity. Up to now, too little information is known about the role of oxidative stress in the pathophysiologic process of acute renal failure in horses with severe rhabdomyolysis. It has been suggested that the oxidative stress might play a role in acute renal failure associated with acute rhabdomyolysis in horses; however, the precise mechanism, whether due to free iron, heme group of myoglobin, heme protein or myoglobin itself and which free radical mechanism is involved, as well as which cellular organelles are affected, are still a matter of debate [1,2].

\section{References}

1. el-Ashker MR (2011) Acute kidney injury mediated by oxidative stress in Egyptian horses with exertional Rhabdomyolysis. Vet Res Commun 35: 311320

2. El-Ashker MR (2011) Diagnostic efficiency of selected biochemical variables to predict the clinical outcome of exertional rhabdomyolysis in Egyptian draft horses. Comp Clin Path.
*Corresponding author: Maged El-Ashker, Lecturer, Department of Internal Medicine and Infectious Diseases, Faculty of Veterinary Medicine, Mansoura University, Mansoura city 35516, Egypt, Tel: 0020174803901; 0020506329195; Fax: 0020502379952; E-mail: maged_elashker@yahoo.com

Received April 26, 2012; Accepted April 26, 2012; Published April 28, 2012

Citation: El-Ashker M (2012) Acute Renal Failure in Horses with Rhabdomyolysis: An Insight into the Role of Oxidative Stress Injury. J Vet Sci Technol 3:e105 doi:10.4172/2157-7579.1000e105

Copyright: (C) 2012 El-Ashker M. This is an open-access article distributed under the terms of the Creative Commons Attribution License, which permits unrestricted use, distribution, and reproduction in any medium, provided the original author and source are credited. 